Article

\title{
Effects of Asian Dust and Phosphorus Input on Abundance and Trophic Structure of Protists in the Southern Yellow Sea
}

\author{
Xi Chen ${ }^{1}{ }^{\oplus}$, Guang-Xing Liu ${ }^{1,2}$, Xiao Huang ${ }^{1,3}$, Hong-Ju Chen ${ }^{1,2}$, Chao Zhang ${ }^{1,2}$ and \\ Yang-Guo Zhao ${ }^{1,2, *}$ \\ 1 College of Environmental Science and Engineering, Ocean University of China, Qingdao 266100, China; \\ asdchenxi180@sina.com (X.C.); gxliu@ouc.edu.cn (G.-X.L.); huangxiao901231@126.com (X.H.); \\ hongjuc@ouc.edu.cn (H.-J.C.);zhangchao@ouc.edu.cn (C.Z.) \\ 2 Key Lab of Marine Environmental Science and Ecology, Ministry of Education, Ocean University of China, \\ Qingdao 266100, China \\ 3 School of Civil and Environmental Engineering, Harbin Institute of Technology (Shenzhen), \\ Shenzhen 518055, China \\ * Correspondence: ygzhao@ouc.edu.cn
}

Received: 16 April 2019; Accepted: 3 June 2019; Published: 7 June 2019

\begin{abstract}
To reveal the effects of Asian dust and phosphorus $(\mathrm{P})$ input on the structure and function of micro-food web in the Yellow Sea, an experiment was conducted onboard the southern Yellow Sea where $\mathrm{P}$ was deficient. The response of the abundance and trophic structure of planktonic protists to different concentrations of dust and $\mathrm{P}$ were studied. The results showed that the sand-dust deposition presented variable effects on different sizes of protists during incubation periods. At the initial stage of incubation with dust, the amount of all sizes of autotrophic protists, especially 10-20 $\mu \mathrm{m}$, were improved; on the contrary, the heterotrophic and mixotrophic protists were inhibited. At the late period, the increase of autotrophic protists was restricted, while the $2-5 \mu \mathrm{m}$ heterotrophic and mixotrophic protists obviously increased. Similarly, adding P demonstrated the obviously positive effect on the 10-20 $\mu \mathrm{m}$ autotrophic protists at the initial period, and then the growth was restricted at the late period. These results were consistent with that of sand-dust deposition. Hence, it could be presumed that the positive effect of sand-dust deposition on autotrophic protists in the southern Yellow Sea was achieved by the release of P from dust. P in the early stage of sand-dust deposition promotes the growth of large-size autotrophic protists, which may accelerate red tides in eutrophic ocean. The stimulation of small-size heterotrophic protists at the late period of sand-dust deposition contributed to the material cycle and food transmission in the ocean. Therefore, the effects of sand-dust deposition on the abundance and trophic structure of different sizes of planktonic protists could change the structure of micro-food web in the southern Yellow Sea and further affected the ecological function of planktonic protists.
\end{abstract}

Keywords: Yellow Sea; sand-dust deposition; protists; trophic structure

\section{Introduction}

The Yellow Sea, as one of the four marginal seas in China, is an area where land, ocean and atmosphere interact more intensely with concentrated human activities and marine economic development. It owns abundant natural resources and developed coastal economy. Previous studies found that the Yellow Sea was intermittently restricted by phosphorus $(P)[1,2]$, which leads to a constant changing process of protists trophic structure in this ocean area, and then altered the ecological functions of protists, such as nutrients utilization and transformation [3,4]. Sand-dust deposition is an 
important pathway for transporting land-based nutrients and pollutants to the ocean and providing nutrients for the marine planktonic protists. Researchers found that sand-dust deposition held a significant positive correlation with chlorophyll $a$ and primary productivity $[5,6]$. Asian dust is an important part of global dust, and the Yellow Sea, located in the downwind zone of the Asian dust source area, is the greatest probability of being affected by Asian dust in China's offshore waters. Some studies showed that Asian dust deposited into the Yellow Sea [6-8] through a long-distance transportation in sand-dust weather, and obvious "fertilization" phenomenon was observed to affect the primary productivity. Thus, Asian sand-dust deposition is an important factor that affects the primary productivity of the Yellow Sea. The nutrients carried by sand-dust [9-12] could alleviate the phosphorus deficiency in the Yellow Sea, thereby affected the abundance and trophic structure of marine biota. However, the effect of sand-dust on the growth of nanoplanktonic protists in the P-limited Yellow Sea has not been reported.

Marine nanoplankton with size ranging 2-20 $\mu \mathrm{m}$, is a key component of marine micro-food web and they play an irreplaceable role in maintaining primary productivity and material cycle [13-15]. It is remarkable that different size groups of nanoplankton (e.g., 2-4, 4-5, 5-7, 7-10 and >10 $\mu \mathrm{m}$ ) revealed different roles in the food web due to the variations of species and proportion [16]. As such, three size groups, i.e., 2-5, 5-10, and 10-20 $\mu \mathrm{m}$ of nanoplankton were proposed in this study. According to the mechanisms of energy and nutrient acquisition, nanoplanktonic protists are divided into autotrophic, heterotrophic (i.e., protozoa) and mixotrophic protists [2,17-19]. Autotrophic nanoplanktonic protists are the key contributor to marine primary productivity [17], Heterotrophic nanoplanktonic protists affect the community structure and function of nanoplankton by preying on bacteria, cyanobacteria or smaller protists [18,19], and being preyed by medium-sized zooplankton [20,21], and then flow to a higher trophic level from the bottom of the food web [22,23]. Mixotrophic nanoplanktonic protists own both the autotrophic and heterotrophic mode, and improve the utilization of nutrients by changing nutritional habits $[2,3,17]$. Hence, the material conversion and energy flow of the marine plankton ecosystem depends on different trophic marine nanoplankton protists. Therefore, it is of great significance to investigate the effects of dust and phosphorus input on the abundance and trophic structure of planktonic protists.

However, there are several blind spots that need to be further revealed in the relationship between the sand-dust and planktonic protists. Firstly, the effect of sand-dust input on nanoplanktonic protists is unknown. Though the sand-dust can provide nutrients during the transport process, it also adsorbs substantial heavy metals such as copper, cadmium, plumbum, and other land-based pollutants, which present a strong toxic effect on plankton [24,25]. Secondly, whether the sand-dust, as a supplement of nutrients, can effectively compensate for P limitation in the Yellow Sea is still unclear. Thirdly, it is difficult to accurately distinguish the ecological functions of different species due to the complexity of marine nanoplanktonic protists.

Hence, in this study, to make a better understanding of the effects of sand-dust and phosphorus on the abundance and trophic structure of different sizes of planktonic protists, an experiment was conducted onboard in the southern Yellow Sea where P was deficient., the corresponding changes of nanoplanktonic protists were following investigated according to the size groups (i.e., 2-5, 5-10, and 10-20 $\mathrm{m}$ ) and trophic types (i.e., autotrophic, heterotrophic and mixotrophic protists) $[3,18,22,26-30]$. The results could provide a scientific supplement for revealing the effects of sand-dust deposition on the trophic structure and ecological function of marine planktonic protists. Meanwhile, this study supply a supplement for further analyzing the effects of sand-dust deposition on marine ecosystems. 


\section{Materials and Methods}

\subsection{Sand-Dust Preparation}

In this study, sand-dust samples were collected from the surface soil of Hunshandake Sandy Land $\left(42^{\circ} 22^{\prime} 28^{\prime \prime} \mathrm{N}, 112^{\circ} 58^{\prime} 34^{\prime \prime} \mathrm{E}\right)$ in May, 2011. The samples were stored at $-20^{\circ} \mathrm{C}$ until use. The large stone in sand-dust samples was eliminated by a sieve with $20 \mu \mathrm{m}$ of pore in diameter and then aged artificially as the previous method [31]. To analyze the concentrations of nutrients, DOC and trace metals in the sand-dust, 30 min of ultra-sonication treatment for the sand-dust was conducted under the temperature of about $0{ }^{\circ} \mathrm{C}$. The contents of nutrients were analyzed by an ion chromatograph (ICS-1100, Dionex Corporation, Bannockburn, IL, USA). Heavy metals were analyzed by an inductively coupled plasma mass spectrometry (ICP-MS-7500c, Agilent Technologies, Palo Alto, CA, USA). Dissolved organic carbon (DOC) was determined by the high temperature combustion oxidation method (TOC-V, Shimadzu Corporation, Kyoto, Japan). The contents of nutrients, DOC and dissolved trace elements in sand-dust are shown in Table 1.

Table 1. Concentrations of nutrients, Dissolved organic carbon (DOC), dissolved trace metals in the sand-dust.

\begin{tabular}{|c|c|c|c|c|c|c|c|c|c|c|c|c|c|}
\hline \multirow{2}{*}{ Ingredients } & \multicolumn{5}{|c|}{ Nutrients and DOC $\left(\mu \mathrm{mol} \mathrm{mg}{ }^{-1}\right)$} & \multicolumn{8}{|c|}{ Dissolved Trace Metals ( $\mu \mathrm{g} \mathrm{g}^{-1}$ ) } \\
\hline & $\mathrm{NO}_{3}^{-}$ & $\mathrm{NO}_{2}^{-}$ & $\mathrm{NH}_{4}{ }^{+}$ & $\mathrm{PO}_{4}{ }^{3-}$ & DOC & $\mathrm{Fe}$ & $\mathrm{Cu}$ & $\mathrm{Zn}$ & $\mathrm{Pb}$ & As & $\mathrm{Ni}$ & $\mathrm{Cd}$ & $\mathrm{Cr}$ \\
\hline Concentration & 0.53 & 0.03 & 0.01 & 0.004 & 7.20 & 473.12 & 0.23 & 4.27 & 0.24 & 0.09 & 7.08 & 0.04 & 0.13 \\
\hline
\end{tabular}

\subsection{Onboard Culturing Experiment}

In November 2014, an onboard artificial sand-dust deposition experiment was carried out on the 'Dongfanghong NO.2' scientific research ship at $\mathrm{H} 03$ station $\left(36^{\circ} 06^{\prime} 00^{\prime \prime} \mathrm{N}, 121^{\circ} 39^{\prime} 00^{\prime \prime} \mathrm{E}\right)$ in the southern Yellow Sea. The location of sampling station H03 is shown in Figure 1. Surface seawater was collected by using a shipborne CTD water collector (USA). The collected seawater was immediately filtered by a silk membrane with pore of $20 \mu \mathrm{m}$, to remove micro, small, medium and large plankton. The filtered seawater was filled into $1.5 \mathrm{~L}$ sterile polyethylene terephthalate (PET) culture bottles and afterwards the bottles were placed in a water tank. The tank was tightly fixed on the deck without shading. The surface seawater from the station H03 was fed into the outer layer tank to maintain the inner bottle temperature and ensure it was the same as the surface water.

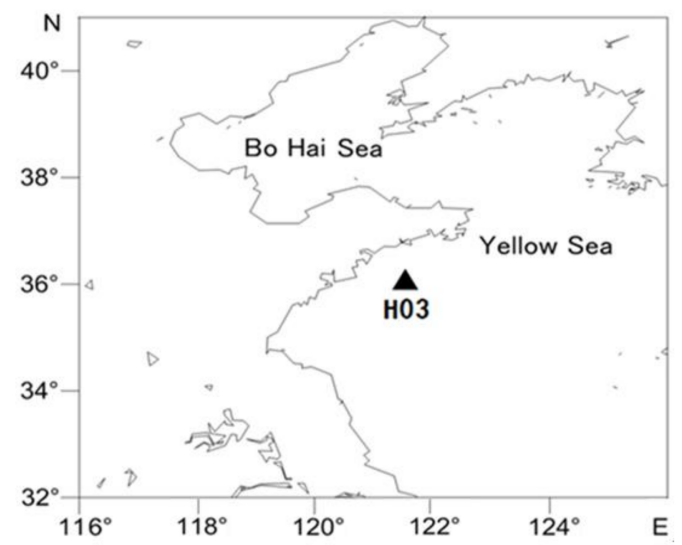

Figure 1. Incubation Station.

The culture experiment was comprised of five groups, i.e., control group, low dust group (LD), high dust group (HD), low phosphorus group (LP), and high phosphorus group (HP). The amounts of added dust or $\mathrm{P}\left(\right.$ as $\mathrm{NaH}_{2} \mathrm{PO}_{4}$ ) referred to the observation data on the Yellow Sea as the previous report [32]. The amount of added dust and $P$ in each experiment group is shown in Table 2. Dust or 
$\mathrm{NaH}_{2} \mathrm{PO}_{4}$ were added only one time immediately after the establishment of the culture system. All culture experiments were conducted triplicate. Samples were taken every day to determine the protists, DOC and inorganic nutrients during the five days' culture period.

Table 2. Experiment design and concentrations of dust and phosphorus.

\begin{tabular}{ccc}
\hline Groups & Treatment & Concentration \\
\hline Control & none & none \\
Low dust group (LD) & dust & $2 \mathrm{mg} / \mathrm{L}$ \\
High dust group (HD) & dust & $20 \mathrm{mg} / \mathrm{L}$ \\
Low phosphorus group (LP) & $\mathrm{NaH}_{2} \mathrm{PO}_{4}$ & $0.2 \mu \mathrm{mol} / \mathrm{L}$ \\
High phosphorus group (HP) & $\mathrm{NaH}_{2} \mathrm{PO}_{4}$ & $1 \mu \mathrm{mol} / \mathrm{L}$ \\
\hline
\end{tabular}

\subsection{Sample Collection and Measurement}

\subsubsection{Nanoplanktonic Protists Samples}

Nanoplanktonic protists samples were collected at 8 a.m. each day during the incubation period. Before sampling, PET culture bottles were slowly inverted for three times to uniformly mix nanoplankton in the incubation system. There was $10 \mathrm{~mL}$ seawater obtained from the culture bottle and then transferred into the sterile freezing tube. Immediately, $10 \%(w / v)$ paraformaldehyde was added into the tube to fix protists (for paraformaldehyde, the final concentration was $0.5 \%(w / v)$ ). After slightly mixing, the tubes were quickly frozen in a liquid nitrogen tank and then transferred to the refrigerator at $-80^{\circ} \mathrm{C}$ for storage. Three parallel samples were taken at one time.

The abundances of different sizes of nanoplanktonic protists were counted by a flow cytometry (BD C6 plus) at different wavelength of fluorescence, as explained by Christaki et al. (2011) [16] and Zubkov et al. (2007) [33]. The sample was stained by SYBR Green I, then determined by flow cytometry with excitation wavelength $488 \mathrm{~nm}$. The trophic mode of the protists was determined by green fluorescence (FL1, $530 \pm 20 \mathrm{~nm}$ ) and red fluorescence (FL3, $>630 \mathrm{~nm}$ ), the protists which showed high FL1 value and low FL3 value were heterotrophic, the protists with high FL1 value and high FL3 value were autotrophic, the rest of protists were mixotrophic. The size of protists were measured by calibration beads $(2,5$ and $10 \mu \mathrm{m})$.

\subsubsection{Dissolved Organic Carbon (DOC)}

The seawater samples were filtered with a high-temperature treated GF/F filter (Whatman, Maidstone, UK) and stored in a high-temperature treated glass bottle at $4{ }^{\circ} \mathrm{C}$ in the dark. The samples were determined by using a total organic carbon meter (TOC-VCPN) [34].

\subsubsection{Inorganic Nutrients}

The seawater samples were filtered by acid treated $0.45 \mu \mathrm{m}$ acetic acid fibre membrane and frozen at $-20{ }^{\circ} \mathrm{C}$ after adding the fixative. The concentrations of different nutrients were determined by QuAAtro nutrient automatic analyzer. $\mathrm{NH}_{4}{ }^{+}$was oxidized by sodium hypochlorite with indigo-phenol blue $(660 \mathrm{~nm}), \mathrm{NO}_{3}{ }^{-}$reduced by copper-cadmium column with naphthalene ethylenediamine hydrochloride $(550 \mathrm{~nm}), \mathrm{NO}_{2}{ }^{-}$with naphthalene ethylenediamine hydrochloride $(550 \mathrm{~nm})$ and $\mathrm{PO}_{4}{ }^{3-}$ with phosphomolybdenum blue $(880 \mathrm{~nm})[32,34]$.

\subsection{Data Processing and Analysis}

Multivariate ANOVA in SPSS Inc. (Chicago, IL, USA) was used to analyze the significant difference of different groups in the culture system. 


\section{Results and Analysis}

At H03 Station, the concentration of DOC is $79.68 \mu \mathrm{mol} / \mathrm{L}$, the concentration of DIN is $2.71 \mu \mathrm{mol} / \mathrm{L}$, and the concentration of $\mathrm{PO}_{4}{ }^{3-}$ is $0.13 \mu \mathrm{mol} / \mathrm{L}$. The $\mathrm{N}: \mathrm{P}$ ration is $21(>16)$ showed that $\mathrm{H} 03$ station was P-limited.

\subsection{Effects of Dust and Phosphorus Addition on the Abundance of Nanoplanktonic Protists}

\subsubsection{Changes of $10-20 \mu \mathrm{m}$ Protists}

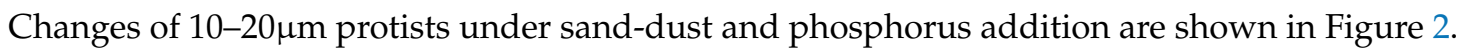
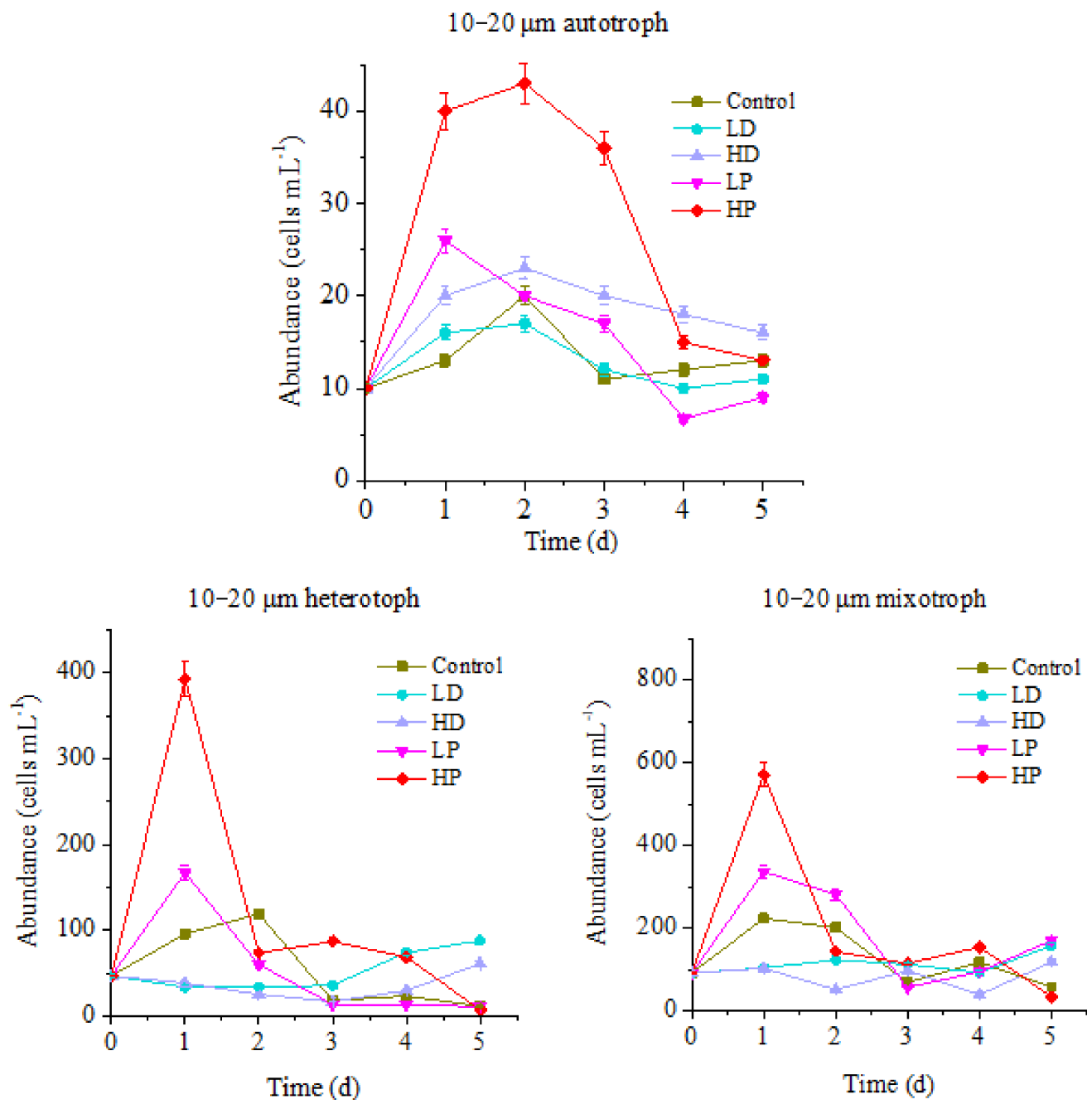

Figure 2. Variations in abundance of 10-20 $\mu \mathrm{m}$ protists.

The changes of 10-20 $\mu \mathrm{m}$ of protists in different concentrations of sand-dust and phosphorus supplementation groups were different from the control. The maximum values of autotrophic and

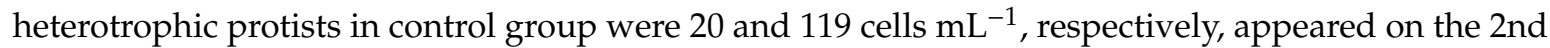
day of incubation. The maximum values of the mixotrophic protists were 223 cells mL ${ }^{-1}$ on the first day of incubation. The peak of HP treated autotrophic protists was 43 cells $\mathrm{mL}^{-1}$, appeared on the 2nd day of incubation, which was significantly higher than that of control $(p<0.05)$. The peaks of HP treated heterotrophic and mixotrophic protists appeared on the 1st day of incubation, 393 and 571 cells $\mathrm{mL}^{-1}$, respectively, which were 3.30 and 2.56 times higher than that of control $(p<0.05)$. The high value lasted for one day and then declined rapidly. The maximum values of LP treatment for autotrophic, heterotrophic and mixotrophic protists were 26,167 , and 336 cells $\mathrm{mL}^{-1}$ on the first day of 
incubation, respectively, which were 1.30, 1.40 and 1.51 times of the control $(p<0.05)$. At the end of incubation, the abundance of mixotrophic protists was 2.98 times higher than that of control $(p<0.05)$.

In summary, the abundances of $10-20 \mu \mathrm{m}$ protists in P supplying groups were higher than the control, and the maximum value of HP treated autotrophic protists was the largest. It showed that the addition of $\mathrm{P}$ will promote the growth of all planktonic protists, especially when the ocean area was P-limited. In the early stage of incubation, the higher concentration of $\mathrm{P}$ led to a stronger growth promoting effect on autotrophic protists; they increased and lasted for a longer time. At the end of incubation, the abundance of all kinds of protists in P-supplemented groups was lower than that in the early stage, and some were even lower than that at the control group. This might be caused by the more rapid consumption of nutrients at the early stage of incubation, and the nutritional deficiency that appeared at the late stage. Therefore, one-time addition of $\mathrm{P}$ could only promote the growth of protists in a short time. If nutrients are not supplied continuously, their growth will be limited, due to lack of nutrients in the later period. Compared with that, the abundance of LP treated mixotrophic protists was higher than that at control group at the late stage, which indicated that the P utilization efficiency of mixotrophic protists in this condition might be higher.

The differences were observed between the three trophic types of protists at the sand-dust addition groups. The abundance of autotrophic protists at HD and LD groups increased first then gradually decreased. The maximum values were 23 and 17 cells $\mathrm{mL}^{-1}$ on the 2 nd day after culture. The maximum value of HD treatment group was 1.15 times higher than the control $(<0.05)$. Although the peak value of HD treatment group was lower than that of $P$ treated group, the value on the last day of incubation was significantly higher than that of $P$ treated group $(<0.05)$. The results showed that the addition of high concentration sand-dust could promote the growth of 10-20 $\mu \mathrm{m}$ autotrophic protists, which might be caused by the continuously supplement $P$ from the sand-dust. The abundances of heterotrophic and mixotrophic protists decreased first and then increased at the sand-dust adding groups. At the initial stage of incubation, they were significantly lower than that of the control and $\mathrm{P}$ adding groups $(p<0.05)$. At the late stage of incubation, the abundance of heterotrophic protists in the two sand-dust groups was higher than that at control and $P$ adding groups. The abundance of mixotrophic protists was higher than that at control and HP groups, but lower than that at LP group. The abundances of heterotrophic and mixotrophic protists in HD treatment group were always higher than that of LD treatment group. Hence, the early sand-dust deposition presented an inhibiting effect on the growth of 10-20 $\mu \mathrm{m}$ heterotrophic and mixotrophic protists, which was ascribed to the toxic effect of the heavy metals and other harmful substances dissolved from the sand-dust [5]. The inhibition effect of sand-dust was much greater than the promotion of $\mathrm{P}$ dissolution. At the late stage of incubation, the sand-dust stimulated the growth of heterotrophic and mixotrophic protists, especially heterotrophic protists. This indicated that the heterotrophic protists gradually tolerated the harmful substances from sand-dust. Furthermore, the nutrients dissolved from the sand-dust including trace elements such as Fe $[8,10,11]$ (Table 1), supplemented the nutrients requirement at the late stage of incubation. The effect of dust was more significant for 10-20 $\mu \mathrm{m}$ heterotrophic and mixotrophic protists at the late stage of culture.

\subsubsection{Response of $5-10 \mu \mathrm{m}$ of Protists to Sand-Dust and Phosphorus Addition}

Changes in the abundance of 5-10 $\mu \mathrm{m}$ of nanoprotists in different trophic modes under the stress of sand and phosphorus addition are shown in Figure 3. 

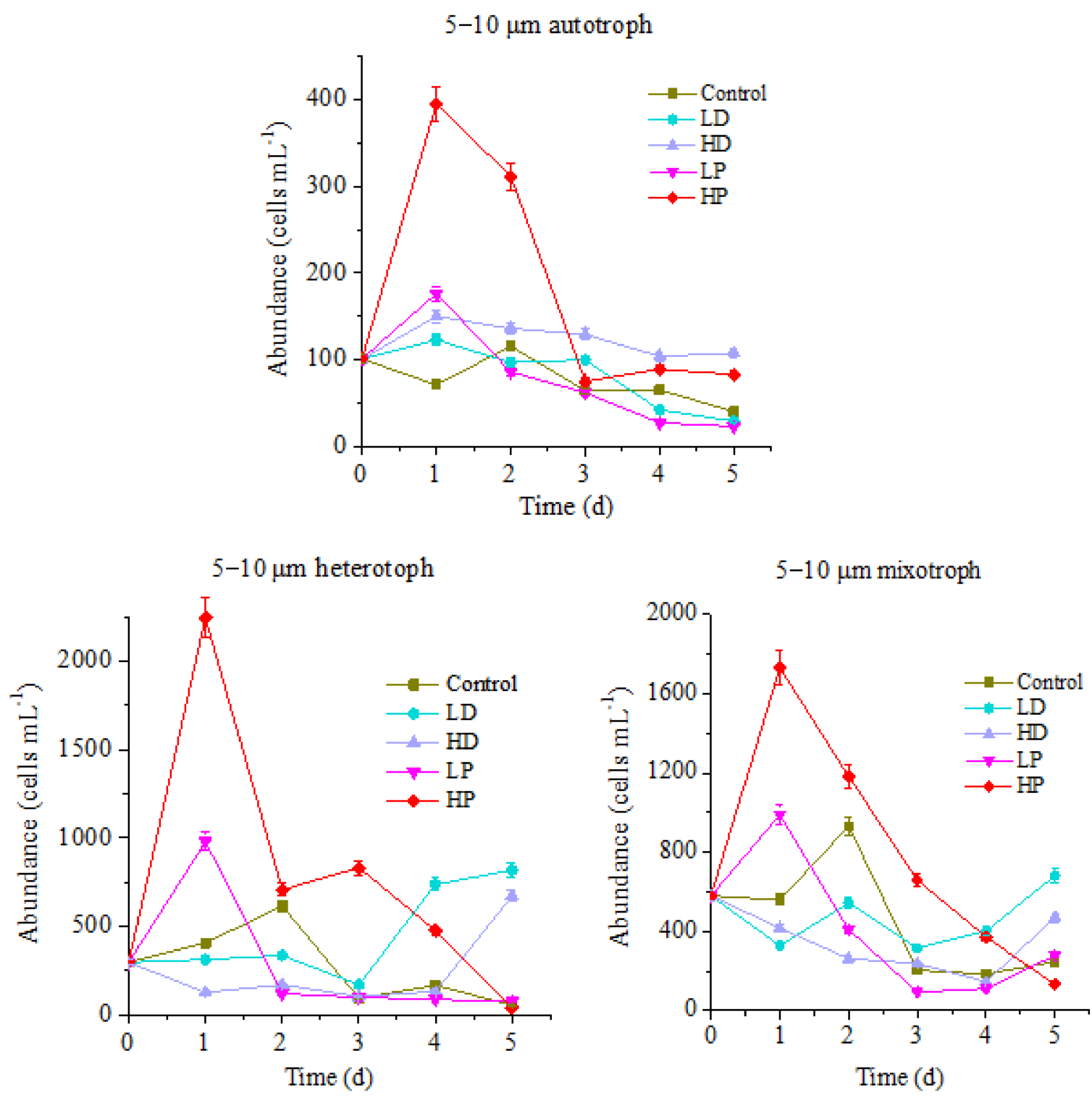

Figure 3. Variation of protists abundance in 5-10 $\mu \mathrm{m}$ size.

The variation trend of the abundance for $5-10 \mu \mathrm{m}$ protists during incubation is basically the same as that of $10-20 \mu \mathrm{m}$ protists, while the variation range is quite different. For the control group, the peak values of autotrophic, heterotrophic and mixotrophic protists appeared on the 2nd day of incubation with the cell concentrations of 116, 615 and 930 cells $\mathrm{mL}^{-1}$, respectively. Compared with that, at HP treatment group, the peak values of autotrophic, heterotrophic and mixotrophic protists were 395, 2245 and 1732 cells $\mathrm{mL}^{-1}$, which were $3.41,3.85$ and 1.86 times higher than those of control $(p<0.05)$. The LP treatment groups followed the peaks of HP treatment. The maximum concentrations of autotrophic, heterotrophic and mixotrophic protists were 176, 980, and 989 cells $\mathrm{mL}^{-1}$, respectively, higher than those at control groups $(p<0.05)$, but they were significantly lower than those at HP treatment group $(p<0.05)$. The abundance decrease of protists in P-supplemented groups at the late stage of incubation might be related to the nutrient deficiency due to their rapid growth at the early stage. As such, it can be referred that the growth of $5-10 \mu \mathrm{m}$ planktonic protists in this ocean is also limited by P. Addition of $\mathrm{P}$ can promote the reproduction of all of the planktonic protists. The higher the concentration of $\mathrm{P}$, the stronger the promotion effect on reproduction of planktonic protists. Compared with responding results of $10-20 \mu \mathrm{m}$ protists to $\mathrm{P}$ addition, it showed that the response of $5-10 \mu \mathrm{m}$ protists to $\mathrm{P}$ addition is faster, but the duration is shorter. 
Similarly, there were also differences between three trophic types of 5-10 $\mu \mathrm{m}$ protists in the sand-dust supplementation groups during the cultivation period. The abundance of autotrophic protists in HD and LD treatment groups increased first and then decreased. Same as P-adding group, the largest value of HD and LD groups appeared on the 1st day of incubation, with the 150 and 123 cells $\mathrm{mL}^{-1}$, respectively. The peak value of autotrophic protists abundance in HD group was 1.29 times higher than that at control group all the time. Nevertheless it was lower than that of P-adding group in the early stage of incubation $(p<0.05)$, and higher than that of P-adding group in the final stage. It showed that the addition of high concentration of sand-dust stimulated the growth of $5-10 \mu \mathrm{m}$ autotrophic protists for a longer time, which might be ascribed to the release of $P$ from sand-dust [6]. The heterotrophic and mixotrophic protists abundance of dust addition groups decreased at the early stage of incubation, which was significantly lower than that at control group and P-adding groups $(p<0.05)$. The higher concentration of dust resulted in a sharper decline, which was confirmed by the fact that heterotrophic and mixotrophic protists abundance of HD treatment groups were always lower than of LD group during all the culture period. Interestingly, at the late stage of incubation, the abundance of two trophic modes protists was higher than that at P-adding groups and control group. Hence, the growth of heterotrophic and mixotrophic protists was significantly inhibited by the sand-dust deposition in the early stage. The higher concentration of dust presented the stronger inhibition effect, which was related to the toxic effect of heavy metals and other harmful substances dissolved from the dust [5]. At the late stage, the growth of protists was promoted, especially for heterotrophs. This might be related to the increase of tolerance for protists to harmful substances and the supplementation of nutrients dissolved from the dust.

\subsubsection{Response of $2-5 \mu \mathrm{m}$ of Protists to Sand-Dust and Phosphorus Addition}

Figure 4 shows that the variation trend of $2-5 \mu \mathrm{m}$ protists abundance is similar to that of above mentioned two sizes of protists, but the variation ranges are quite different. For the control group, the maximum values of autotrophic, heterotrophic and mixotrophic protists appeared on the 2nd day of culture, which were 4071,9491 and 11,965 cells $\mathrm{mL}^{-1}$, respectively. However, the peak values of $P$ supplementation groups mainly emerged on the 1st day of culture. The highest values of HP treated autotrophic, heterotrophic and mixotrophic protists were 9303, 18,867 and 23,501 cells $\mathrm{mL}^{-1}$, which were significantly higher than those of control $(p<0.05)$. The maximum values of LP treated three trophic modes protists were 6245,11618 and 15,240 cells $\mathrm{mL}^{-1}$, respectively, higher than those of control $(p<0.05)$, but lower than those at HP group $(p<0.05)$. It can be seen that the growth of $2-5 \mu \mathrm{m}$ planktonic protists in this ocean area was also restricted by $\mathrm{P}$. The addition of $\mathrm{P}$ could promote the growth of planktonic protists of different trophic modes. Comparably, the response of 2-5 $\mu \mathrm{m}$ planktonic protists to $P$ addition was faster than that of $10-20 \mu \mathrm{m}$ protists, and the duration lasts longer on HP treated heterotrophic and mixotrophic protists.

The changes of $2-5 \mu \mathrm{m}$ protists abundance of different trophic modes in the sand-dust addition groups were different. The highest abundance of HD and LD treated autotrophic protists appeared on the 1st day of culture, same as that of P-adding groups, with the maximum values of 4860 and 4255 cells $\mathrm{mL}^{-1}$, respectively. The peak value of HD group was significantly higher than that at control group, but lower than that at P-adding group $(p<0.05)$. At the late stage of incubation, HD group was higher than those at control and P-adding groups, indicating that the addition of high concentration sand-dust benefits to the growth of $2-5 \mu \mathrm{m}$ autotrophic protists. This result might be related to the dissolution of $P$ from sand-dust [6]. For the heterotrophic and mixotrophic protists, the concentration decreased at the early stage of incubation, which was significantly lower than that at control group and P-adding groups $(p<0.05)$. At the end of cultivation, the abundance of heterotrophic and mixotrophic protists increased, and got higher than those at control and the P-adding groups, especially heterotrophic protists in the LD group was 2.98 times higher than at control group. The result showed that the growth of $2-5 \mu \mathrm{m}$ heterotrophic and mixotrophic protists, especially heterotrophic protists, was also inhibited by the sand-dust at the initial of incubation, then been promoted in the late stage. 
$2-5 \mu \mathrm{m}$ autotroph

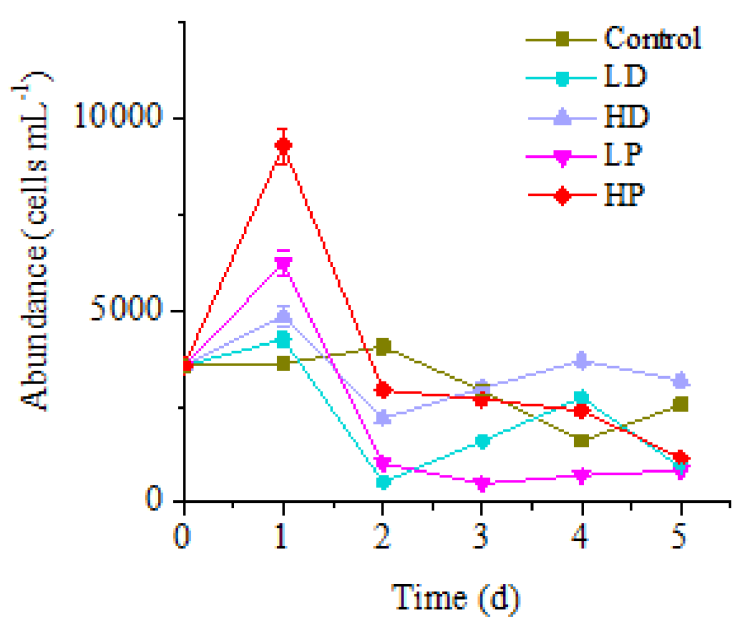

\section{2-5 $\mu \mathrm{m}$ heterotoph}

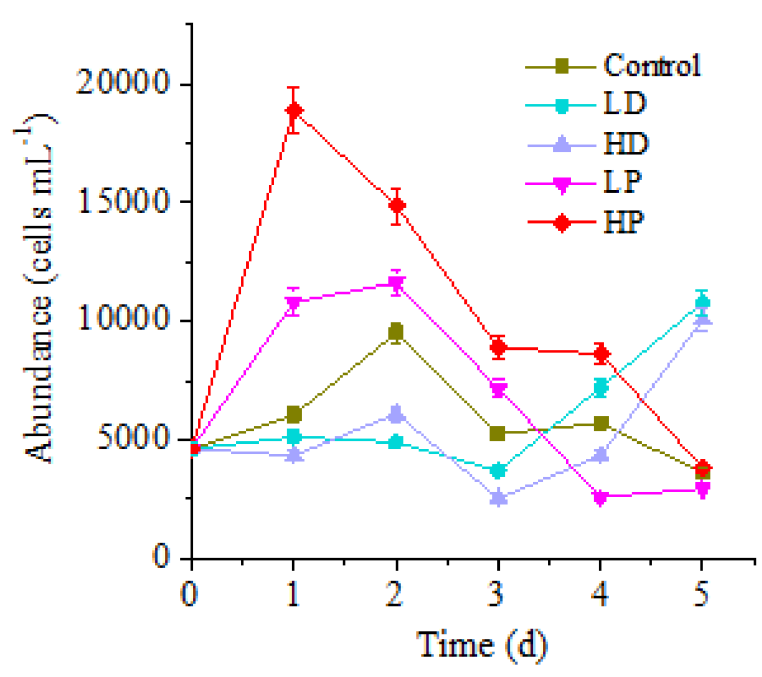

2-5 $\mu$ m mixotroph

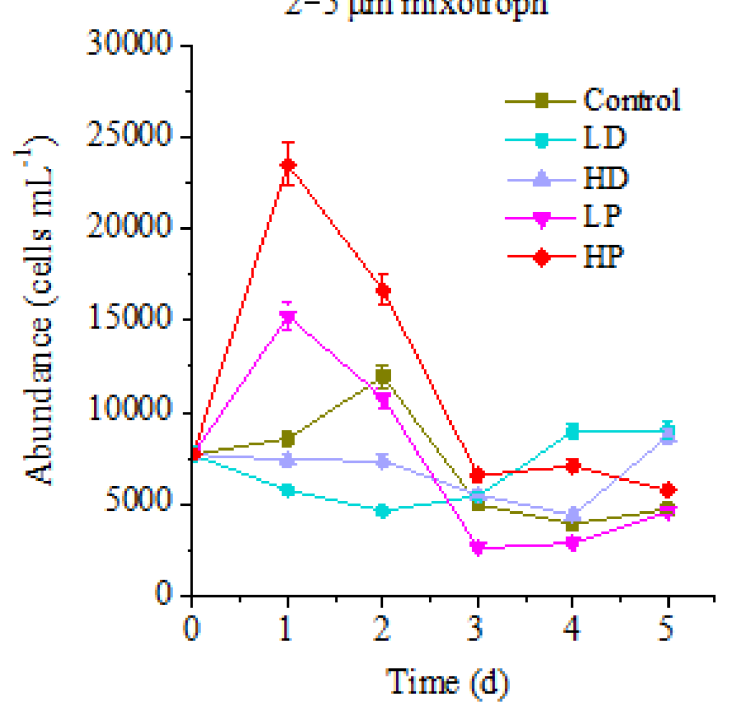

Figure 4. Variation of protists abundance in $2-5 \mu \mathrm{m}$ size.

\subsection{Effects of Sand-Dust and Phosphorus Addition on the Composition of Protists}

\subsubsection{Effects of Dust and Phosphorus Dosage on Trophic Structure of 10-20 $\mu \mathrm{m}$ Protists}

The changes of trophic structure of 10-20 $\mu \mathrm{m}$ protists under the addition of dust and phosphorus are shown in Figure 5. The mixotrophic protists predominated in each group, accounting for $63.33 \%$ on average, followed by heterotrophic protists, accounting for $30.68 \%$ on average. On the 1 st day of culture, the peak value of heterotrophic protists was appeared at P-supplemented groups and the growth rate was higher than that at other groups. On the 1st day of HP addition culture, the proportion of heterotrophic protists was higher than that at control group with $10.23 \%$, and the proportion of mixotrophic protists was lower than that of the control group with $10.30 \%(p<0.05)$, the proportion of autotrophic protists did not change obviously. At the end of the culture, the proportion of autotrophic protists at HP group increased by $8.02 \%(p<0.05)$ because its high growth rate maintained for a long time, and the proportion of mixotrophic protists decreased by $7.41 \%(p<0.05)$. The proportions of heterotrophic protists had no significant difference among different experimental groups $(p>0.05)$. The results showed that the autotrophic protists over competed heterotrophic protists and mixotrophic protists under the $\mathrm{P}$ dosage condition and thus the proportion of autotrophic protists increased significantly. 


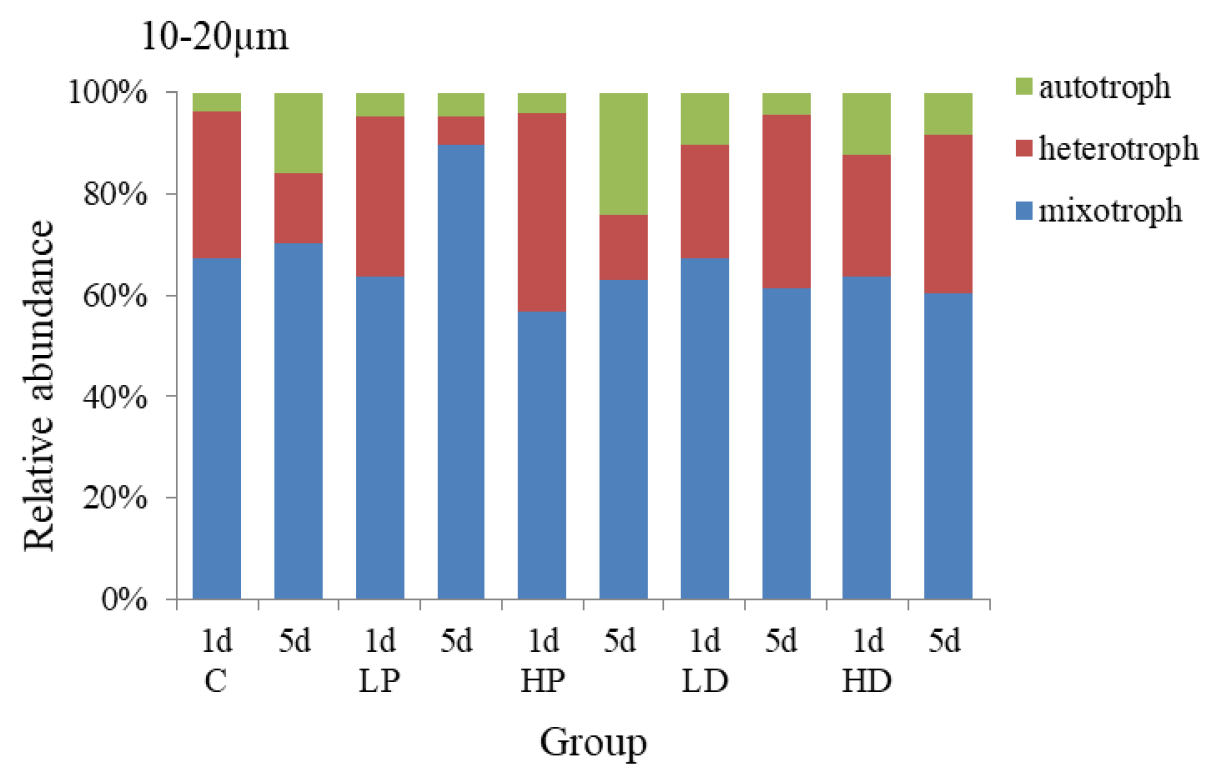

Figure 5. Variation in the trophic structure of protists in 10-20 $\mu \mathrm{m}$ size.

The trophic structure of 10-20 $\mu \mathrm{m}$ protists in sand-dust addition groups was different from that of $\mathrm{P}$ addition groups. Compared with the control group, the proportion of autotrophic protists increased at the initial stage of cultivation, while the growth of heterotrophic and mixotrophic protists was inhibited, and the higher the concentration of sand-dust lead to the stronger effect. On the 1st day, the proportion of autotrophic protists at HD group increased by $8.58 \%(p<0.05)$, while the proportion of heterotrophic protists and mixotrophic decreased compared with that of control group $(p<0.05)$. However, at the end of culture, the growth rate of autotrophic protists decreased due to the significant increase of the heterotrophic growth rate at sand-dust group, which made the proportion of heterotrophic protists in sand-dust group higher than that at control group by $17.86 \%(p<0.05)$, and significantly higher than that of $\mathrm{P}$ addition, and the proportion of autotrophic and mixotrophic protists decreased by $7.80 \%$ and $10.06 \%$, respectively, compared with the control group. The results showed that the sand-dust could stimulate the growth of autotrophic protists at early stage, but inhibit the heterotrophic protists significantly. At the late stage, sand-dust presented a stronger promoting effect on the heterotrophic protists.

\subsubsection{Effects of Dust and Phosphorus Dosage on Trophic Structure of 5-10 $\mu \mathrm{m}$ Protists}

The response of trophic structure of 5-10 $\mu \mathrm{m}$ protists to dust and phosphorus dosage is shown in Figure 6. It showed that mixotrophic protists and heterotrophic protists were the dominant species, accounting for $45.74 \%$ and $44.88 \%$ of the total abundance. The relative abundance of autotrophic protists was relatively small, accounting for $9.38 \%$ on average. Compared with 10-20 $\mu \mathrm{m}$ groups, the proportion of $5-10 \mu \mathrm{m}$ mixotrophic protists decreased by $17.59 \%(p<0.05)$, while the proportion of heterotrophic protists increased by $14.20 \%(p<0.05)$. On the first day of incubation, the growth of heterotrophic protists was higher, the proportion of mixotrophic protists reduced. At HP treatment group, heterotrophic protists increased by $12.16 \%(p<0.05)$, mixotrophic protists decreased by $14.34 \%$ $(p<0.05)$, and autotrophic protists decreased slightly $(p>0.05)$, compared with control group. At the end of culture, at HD addition group, the proportion of heterotrophic protists increased by $20.47 \%$ $(p<0.05)$, the proportion of mixotrophic protists decreased by $20.58 \%(p<0.05)$, and the proportion of heterotrophic protists presented little change $(p>0.05)$, compared with the control groups, respectively. Hence, the 5-10 $\mu \mathrm{m}$ heterotrophic protists were more sensitive to P addition in the early stage of culture and more competitive than the mixed and autotrophic protists. However, at the end of culture, the autotrophic protists became more competitive and their proportion increased significantly, indicating that $\mathrm{P}$ dosage had a stronger and longer effect on the growth of autotrophic protists. 


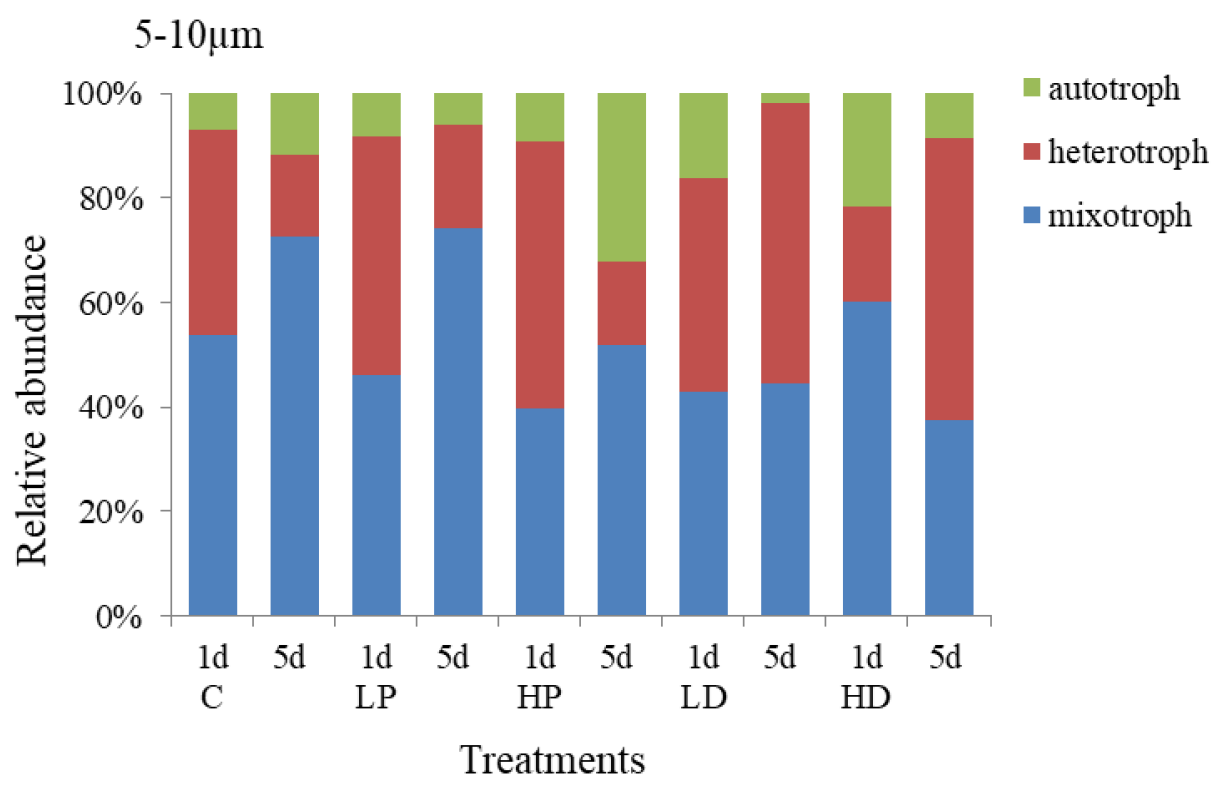

Figure 6. Variation in the trophic structure of protists in 5-10 $\mu \mathrm{m}$ size.

The trophic structure of 5-10 $\mu \mathrm{m}$ protists under sand-dust addition was different from that of $\mathrm{P}$ addition. The change of autotrophic protists in sand-dust adding group was the same as that of the $P$ adding group. On the first day of culture, the autotrophic protists increased significantly and the higher concentration sand-dust led to the higher scale increase. At the initial stage of culture, the proportion of autotrophic protists at LD and HD groups increased to $16.10 \%$ and $21.65 \%$ respectively, which was $9.25 \%$ and $14.79 \%$ higher than that at control group $(p<0.05)$, but the growth of heterotrophic and mixotrophic protists were significantly inhibited $(p<0.05)$. At the end of culture, the proportion of heterotrophic protists at LD and HD groups increased to $53.50 \%$ and $53.76 \%$ respectively, $37.71 \%$ and $37.97 \%$ higher than that at control group $(p<0.05)$. These increases were significantly higher than that at P-supplemented groups $(p<0.05)$. Meanwhile, the proportion of autotrophic and mixotrophic protists decreased, especially for the HD and LD treatments, they were $34.91 \%$ and $27.91 \%$ lower than those at control group $(p<0.05)$. The results showed that the early stage of sand-dust dosage had obvious promoting effect on the growth of autotrophic protists, but inhibited the heterotrophic protists. At the late stage, it presented stronger promoting effect on the heterotrophic protists.

\subsubsection{Effects of Dust and Phosphorus Dosage on Trophic Structure of $2-5 \mu \mathrm{m}$ Protists}

Changes in the composition and trophic structure of 2-5 $\mu \mathrm{m}$ protists under sand-dust and phosphorus addition stress are shown in Figure 7. The results showed that the mixotrophic protists dominated in $2-5 \mu \mathrm{m}$ protists, accounting for $45.11 \%$ of the total abundance, the heterotrophic followed by $37.00 \%$, and the autotrophic was about $17.89 \%$. Compared with the $10-20 \mu \mathrm{m}$ and $5-10 \mu \mathrm{m}$ protists, the autotrophic increased by $11.89 \%$ and $8.50 \%$, respectively, meaning which reflected that the trophic structure of 2-5 $\mu \mathrm{m}$ protists were more balanced than other sizes. On the 1st day, the protists trophic structure in $\mathrm{P}$ adding groups did not change obviously compared with control group, but at the end of culture, the proportion of HP and LP treated mixotrophic protists increased by $10.22 \%$ and $11.43 \%$ respectively. While the autotrophic protists decreased by $12.55 \%$ and $13.41 \%$, respectively. The results showed that $\mathrm{P}$ addition presented little effect on the trophic structure of protists at the early stage, but decreased the proportion of the autotrophic and increased the proportion of the mixotrophic at the late stage.

The trophic structure of 2-5 $\mu \mathrm{m}$ protists under sand-dust adding changed largely. At the early stage, the effect of sand-dust addition on the autotrophic presented the same trend as that of $P$ addition compared with the control. Both $\mathrm{P}$ and sand-dust adding improved the proportion of the 
autotrophic protists. The relative abundance of autotrophic protists at LD and HD treated groups were $28.15 \%$ and $29.26 \%$, respectively, which increased by $8.23 \%$ and $9.15 \%$ comparing with the control. However, the growth of heterotrophic and mixotrophic protists was inhibited. At the end of incubation, the proportion of heterotrophic protists increased to $52.04 \%$ and $45.94 \%$ at LD and HD treatment groups, respectively, $18.80 \%$ and $12.70 \%$ higher than that at control group. The proportion of the autotrophic protists at LD and HD treatment groups decreased to $4.40 \%$ and $14.49 \%$, respectively, which was $19.05 \%$ and $8.97 \%$ lower than that at control group. The results showed that the sand-dust deposition had a positive effect on the growth of $2-5 \mu \mathrm{m}$ autotrophic protists at the early stage, but increased the proportion of the heterotrophic protists at the late stage.

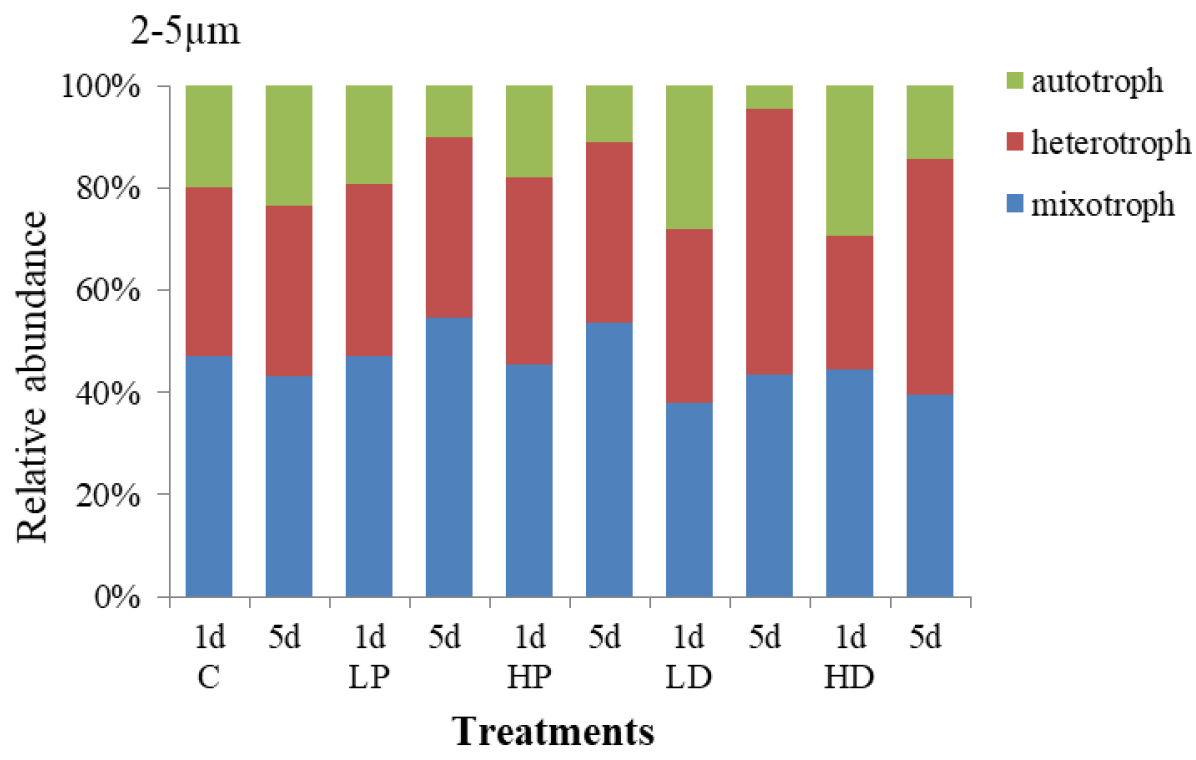

Figure 7. Variation in the trophic structure of protists in $2-5 \mu \mathrm{m}$ size.

\section{Discussion}

According to the changes of relative abundance and trophic structure of protists by the rank sum test of Kruskal-wallis and Nemenyi-Wilcoxon-Wilcox, it showed that P promoted the growth of protists with the different particle sizes and the trophic modes at the early stage of culture. While the sand-dust presented different effects on the growth of different trophic modes. It stimulated the autotrophic but inhibited the heterotrophic and mixotrophic protists. The order of relative abundance of autotrophic protists with different particle sizes was 10-20 $\mu \mathrm{m}>5-10 \mu \mathrm{m}>2-5 \mu \mathrm{m}$. The order of decreasing the proportion of heterotrophic protists with different particle sizes was $5-10 \mu \mathrm{m}$ $>10-20 \mu \mathrm{m}>2-5 \mu \mathrm{m}$; and the order of inhibiting the proportion for mixotrophic protists with different particle sizes was 10-20 $\mu \mathrm{m}>5 \mu \mathrm{m}>2-5 \mu \mathrm{m}$. The early stage of sand-dust deposition obviously inhibited the heterotrophic and mixotrophic protists by the dissolution of toxic and harmful substances in sand-dust. Mixotrophic and heterotrophic protists are the primary predator of autotrophic protists; Pearce et al. (2011) found $42 \% \sim 82 \%$ primary production was consumed by mixotrophic and heterotrophic protists [35]. The decrease of mixotrophic and heterotrophic protists could accelerate the growth of autotrophic protists. In this study, sand-dust addition promoted the growth of autotrophic protists at the early stage, and the decrease of mixotrophic and heterotrophic protists accelerated this process. The further study confirmed that sand-dust storm could significantly induce the occurrence of red tide in the southern Yellow Sea $[18,30]$. Besides, the harmful inhibiting effect of sand-dust on heterotrophic protists community would weaken the marine matter cycle and food transfer efficiency.

At the late stage of culture, P presented a prohibitive effect on the growth of protists, which was related to the rapid growth of protists at the earlier stage, which resulted in nutritional deficiency and growth restriction at the late stage. In the late stage of sand-dust deposition, the autotrophic protists 
were limited due to the excessive growth of autotrophic protists in the earlier stage. At the late stage, sand-dust demonstrated stimulating effect for heterotrophic and mixotrophic protists, and the order was heterotrophic $>$ mixotrophic protists. As for the heterotrophic protists with different particle sizes, the order was 5-10 $\mu \mathrm{m}>2-5 \mu \mathrm{m}>10-20 \mu \mathrm{m}$, and for mixotrophic protists, the order was 10-20 $\mu \mathrm{m}$ $>5-10 \mu \mathrm{m}>2-5 \mu \mathrm{m}$. In the late stage of sand-dust deposition, the toxicity of harmful substances to heterotrophic protists gradually weakened. These protists slowly adapted to the sand-dust environment and dissolution of organic substances and other nutrients in sand-dust provided abundant nutrients for the heterotrophic protists [17]. As such, their abundance maintained stable and their proportion gradually increased. The effects of low sand-dust group and high sand-dust group on the proportion of heterotrophic and mixotrophic protists were basically coincident. However, the effect of high sand-dust group was stronger and the nutritional supplementation lasted longer in the later period.

For the trophic structure, at the early stage of incubation, $\mathrm{P}$ addition could promote all kinds of phytoplankton protists, especially the 10-20 $\mu \mathrm{m}$ autotrophic protists, which were consistent with that of autotrophic protists at the early stage of sand-dust deposition. At the late stage of incubation, both $P$ addition and sand-dust deposition restricted all sizes of autotrophic protists. Therefore, it is speculated that the effect of sand-dust deposition on the autotrophic protists in this ocean were ascribed to the dissolution of $\mathrm{P}$ from sand-dust. The early promotion of sand-dust was to supplement the $\mathrm{P}$ in the sea area, while at the late stage, the inhibition for the autotrophic protists was mainly related to the early rapid growth of autotrophic protists by consuming up the $\mathrm{P}$ and other nutrients. The limiting capacity of the sand-dust group at the late stage is less than that at P-adding groups. This reflected that the dust could continuously supply the $\mathrm{P}$ and other nutrients.

The abundant $P$ at the early stage of sand-dust deposition promoted the rapid growth of large-size autotrophic protists. This phenomenon will further accelerate the occurrence of red tides in eutrophic sea areas. Sand-dust deposition in the late stage stimulated the small-size heterotrophic protists and accelerated the material cycle efficiency and food transfer capacity in the sea. Therefore, the influence of sand-dust on the structure of different particle size and trophic protists will change the structure of the micro-food web in the ocean. It will also change ability of material transformation in the water body and ultimately, and affect the ecological function of protists in the transforming matter and producing food in the sea.

\section{Conclusions}

(1) Sand-dust deposition affected the trophic structure of different particle sizes of planktonic protists in the southern Yellow Sea. This could lead to change the structure of micro-food webs in the sea, and affect the ecological functions of micro-food webs in material transformation and food production.

(2) The growth of planktonic protists of all trophic modes in this ocean was restricted by $P$. The early addition of $\mathrm{P}$ could promote the growth of planktonic protists of all trophic modes in the southern Yellow Sea. The effect on the10-20 $\mu \mathrm{m}$ autotrophic protists was most obviously, while the late addition of $\mathrm{P}$ mainly restricted the growth of different sizes of protists.

(3) The effect of initial sand-dust deposition on autotrophic protists was the same as that of $P$, it inhibited heterotrophic and mixotrophic protists. The positive effect of sand-dust deposition on heterotrophic and mixotrophic protists was strong at the late stage, and it improved the abundance of small-sized heterotrophic protists.

(4) The positive effect of sand-dust deposition on autotrophic protists in the Yellow Sea might be related to the dissolution of $\mathrm{P}$ from the sand-dust. The promotion of small-size heterotrophic protists in the late stage of sand-dust deposition could accelerate the material circulation efficiency and food transformation in the sea. 
Author Contributions: Conceptualization, X.C. and Y.-G.Z.; methodology, X.C., G.-X.L. and H.-J.C.; investigation, X.C., H.-J.C., and C.Z.; formal analysis, X.C. and C.Z.; project administration; G.-X.L. and H.-J.C.; resources, G.-X.L. and H.-J.C.; software, X.C.; supervision, G.-X.L.; writing-original draft preparation, X.C., and Y.-G.Z.; writing-review and editing, X.C., Y.-G.Z. and X.H.; funding acquisition, G.-X.L.; validation, G.-X.L.; visualization, X.C and X.H.

Funding: Financial support for this project was provided by the National Natural Science Foundation of China (NSFC; 41210008) and the Major State Basic Research Development Program of China (973 Program; 2014CB953701). This study was conducted at the Ocean University of China.

Conflicts of Interest: The authors declare no conflict of interest.

\section{References}

1. Wang, B.D.; Wang, G.Y. Horizontal distributions and transportation of nutrients in the southern Huanghai Sea. Acta Oceanol. Sin. 1999, 21, 124-129.

2. Xie, L.P.; Sun, X.; Wang, B.D.; Xin, M. Temporal and spatial distributions of trophic structure and potential nutrient limitation in the Bohai Sea and the Yellow Sea. Mar. Sci. 2012, 36, 45-53.

3. Ghyoot, C.; Lancelot, C.; Flynn, K.J.; Mitra, A.; Gypens, N. Introducing mixotrophy into a biogeochemical model describing an eutrophied coastal ecosystem. Prog. Oceanogr. 2017, 157, 1-11. [CrossRef]

4. Stoecker, D.K. Conceptual models of mixotrophy in planktonic protists and some ecological and evolutionary implications. Eur. J. Protistol. 1998, 34, 281-290. [CrossRef]

5. Griffin, D.W.; Kellogg, C.A. Dust storms and their impact on ocean and human health: Dust in earth's atmosphere. EcoHealth 2004, 1, 284-295. [CrossRef]

6. Richon, C.; Dutay, J.; Dulac, F.; Dulac, F.; Wang, R.; Balkanski, Y.; Nabat, P.; Aumont, O.; Desboeufs, K.; Laurent, B.; et al. Modeling the impacts of atmospheric deposition of nitrogen and desert dust-derived phosphorus on nutrients and biological budgets of the Mediterranean Sea. Prog. Oceanogr. 2018, 163, 21-39. [CrossRef]

7. Zhang, K.; Gao, H.W. The characteristics of Asian-dust storms during 2000-2002: From the source to the sea. Atmos. Environ. 2007, 41, 9136-9145.

8. Tan, S.C.; Shi, G.Y.; Wang, H. Long-range transport of spring dust storms in Inner Mongolia and impact on the China seas. Atmos. Environ. 2012, 46, 299-308. [CrossRef]

9. Tan, S.C.; Shi, G.Y.; Shi, J.H.; Gao, H.W.; Yao, X.H. Correlation of Asian dust with chlorophyll and primary productivity in the coastal seas of China during the period from 1998 to 2008. J. Geophys. Res. 2011, 116, G02029. [CrossRef]

10. Tan, S.C.; Shi, G.Y. The relationship between satellite-derived primary production and vertical mixing and atmospheric inputs in the Yellow Sea cold water mass. Cont. Shelf. Res. 2012, 48, 138-145. [CrossRef]

11. Tan, S.C.; Wang, H. The transport and deposition of dust and its impact on phytoplankton growth in the Yellow Sea. Atmos. Environ. 2014, 99, 491-499. [CrossRef]

12. Gao, Y.; Arimoto, R.; Duce, R.A.; Lee, D.S.; Zhou, M.Y. Input of atmospheric trace elements and mineral matter to the Yellow Sea during the spring of a low-dust year. J. Geophys. Res. 1992, 97, 3767-3777. [CrossRef]

13. Azam, F.; Fenchel, T.; Field, J.G.; Gray, J.S.; Meyer-Reil, L.A.; Thingstad, F. The ecological role of water-column microbes in the sea. Mar. Ecol. Prog. Ser. 1983, 10, 257-263. [CrossRef]

14. Hagstrǒm, A.; Azam, F.; Anderson, A.; Wikner, J.; Rassoulzadegan, F. Microbial loop in an oligotrophic pelagic marine ecosystem: Possible roles of cyanobacteria and nanoflagellates in the organic fluxes. Mar. Ecol. Prog. Ser. 1988, 49, 171-178. [CrossRef]

15. Sherr, E.B.; Sherr, B.F. Bacterivory and herbivory: Key roles of phagotrophic protists in pelagic food webs. Microb. Ecol. 1994, 28, 223-235. [CrossRef] [PubMed]

16. Christaki, U.; Courties, C.; Massana, R.; Catala, P.; Lebaron, P.; Gasol, J.M.; Zubkov, M. Optimized routine flow cytometric enumeration of heterotrophic flagellates using SYBR Green I. Limnol. Oceanogr. Meth. 2011, 9, 329-339. [CrossRef]

17. Lin, Y.C.; Tsai, A.Y.; Chiang, K.P. Trophic coupling between Synechococcus and pigmented nanoflagellates in the coastal waters of Taiwan, Western Subtropical Pacific. J. Oceanogr. 2009, 65, 781-789.

18. Mitra, A.; Flynn, K.J.; Tillmann, U.; Raven, J.A.; Caron, D.; Stoecker, D.K.; Not, F.; Hansen, P.J.; Hallegraeff, G.; Sander, R.W.; et al. Defining planktonic protist functional groups on mechanisms for energy and nutrient acquisition: Incorporation of diverse mixotrophic strategies. Protists 2016, 167, 106-120. [CrossRef] [PubMed] 
19. Sherr, E.B.; Sherr, B.F. Significance of predation by protists in aquatic microbial food webs. Antonie Van Leeuwenhoek 2002, 81, 293-308. [CrossRef] [PubMed]

20. Stoecker, D.K.; Capuzzo, J.M. Predation on protozoa: Its importance to zooplankton. J. Plankton Res. 1990, 12, 891-908. [CrossRef]

21. Jeong, H.J.; Song, J.E.; Kang, N.S.; Kim, S.; Yoo, Y.D.; Park, J.Y. Feeding by heterotrophic dinoflagellates on the common marine heterotrophic nanoflagellate Cafeteria sp. Mar. Ecol. Prog. Ser. 2007, 333, 151-160. [CrossRef]

22. Sato, M.; Yoshikawa, T.; Takeda, S.; Furuya, K. Application of the size-fractionation method to simultaneous estimation of clearance rates by heterotrophic flagellates and ciliates of pico- and nanophytoplankton. J. Exp. Mar. Bio. Ecol. 2007, 349, 334-343. [CrossRef]

23. Sinistro, R. Top-down and bottom-up regulation of planktonic communities in a warm temperate wetland. J. Plankton Res. 2010, 32, 209-220. [CrossRef]

24. Cheng, T.T.; Lü, D.R.; Chen, H.B.; Wang, G.C. Size distribution and element composition of dust aerosol in Chinese Otindag Sandland. Chin. Sci. Bull. 2005, 50, 788-792. [CrossRef]

25. Duan, J.C.; Tan, J.H. Atmospheric heavy metals and Arsenic in China: Situation, sources and control policies. Atmos. Environ. 2013, 4, 93-101. [CrossRef]

26. Sherr, B.F.; Sherr, E.B. Proportional distribution of total numbers, biovolume, and bacterivory among size

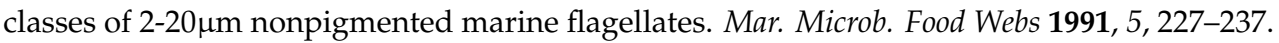

27. Christaki, U.; Courties, C.; Joux, F.; Jeffrey, W.H.; Neveux, J.; Naudin, J. Community structure and trophic role of ciliates and heterotrophic nanoflagellates in Rhone River diluted mesoscale structures (NW Mediterranean Sea). Aquat. Microb. Ecol. 2009, 57, 263-277. [CrossRef]

28. Mitra, A.; Flynn, K.J.; Burkholder, J.; Berge, T.; Calber, A.; Raven, J.A.; Granéli, E.; Gilvert, P.M.; Hansen, P.J.; Stoecker, D.K.; et al. The role of mixotrophic protists in the biological carbon pump. Biogeosciences 2014, 11, 995-1005. [CrossRef]

29. Caron, D.A.; Alexander, C.H.; Allen, A.E.; Archibald, J.M.; Arrmbrust, E.V.; Bachy, C.; Bell, C.J.; Bharti, A.; Dyhrman, S.T.; Guida, S.M.; et al. Probing the evolution, ecology and physiology of marine protists using transcriptomics. Nat. Rev. Microbiol. 2017, 15, 6-20. [CrossRef]

30. Stibor, H.; Stockenreiter, M.; Nejstgaard, J.C.; Ptacnik, R.; Sommer, U. Trophic switches in pelagic systems. Curr. Opin. Syst. Biol. 2019, 13, 108-114. [CrossRef]

31. Guieu, C.; Dulac, F.; Desboeufs, K.; Wagener, T.; Pulido-Villena, E.; Grisoni, J.; Louis, F.; Ridame, C.; Blain, S.; Brunet, C.; et al. Large clean mesocosms and simulated dust deposition: A new methodology to investigate responses of marine oligotrophic ecosystems to atmospheric inputs. Biogeosciences 2010, 7, 2765-2784. [CrossRef]

32. Shi, J.H.; Gao, H.W.; Zhang, J.; Tan, S.C.; Ren, J.L.; Liu, C.G.; Liu, Y.; Yao, X.H. Examination of causative link between a spring bloom and dry/wet deposition of Asian dust in the Yellow Sea. Chin. J. Geophys. Res. 2012, 117, D17304. [CrossRef]

33. Zubkov, M.V.; Burkill, P.H.; Topping, J.N. Flow cytometric enumeration of DNA-stained oceanic planktonic protists. J. Plankton Res. 2007, 29, 79-86. [CrossRef]

34. Knap, A.; Michaels, A.; Close, A. Protocols for the Joint Global Ocean Flux Study (JGOFS) Core Measurement. In Scientific Committee on Oceanic Research Manual and Guides; UNESCO: Paris, France, 1994; Volume 29, pp. 210-243.

35. Pearce, I.; Davidson, A.T.; Thomson, P.G.; Wright, S.; Enden, R. Marine microbial ecology in the sub-Antarctic Zone: Rates of bacterial and phytoplankton growth and grazing by heterotrophic protists. Deep Sea Res. Part II 2011, 58, 2248-2259. [CrossRef]

(C) 2019 by the authors. Licensee MDPI, Basel, Switzerland. This article is an open access article distributed under the terms and conditions of the Creative Commons Attribution (CC BY) license (http://creativecommons.org/licenses/by/4.0/). 